\title{
BILATERAL FRACTURE-SEPARATIONS OF THE DISTAL RADIAL EPIPHYSES DURING WEIGHT-LIFTING
}

\section{N. H. JENKINS, FRCS and W. J. MINTOWT-CZYZ, FRCS}

Dept. of Orthopaedic and Trauma Surgery, Cardiff Royal Infirmary

Key words: Radius fractures, Tibial fractures, Epiphyses, Weight-lifting.

\section{INTRODUCTION}

Unsupervised weight-lifting is dangerous and is prohibited at schools and sports clubs. This report describes the case of a thirteen year old boy who, after sustaining bilateral fracture-separations of the distal radial epiphyses during weight-lifting, suffered a fracture of the distal tibial epiphysis in a football injury a fortnight later.

\section{CASE REPORT}

A thirteen year old boy (at the 80th percentile for height and weight) was weight-lifting, alone, in a makeshift gymnasium at his parents' house. As he approached the apex of a lift, the barbell weighing $30 \mathrm{~kg}$ passed posterior to his centre of gravity and began to pull him over backwards. In attempting to retrieve the situation he felt the sudden onset of pain in both wrists as they were forced into hyperextension. Radiographs in the Casualty Department
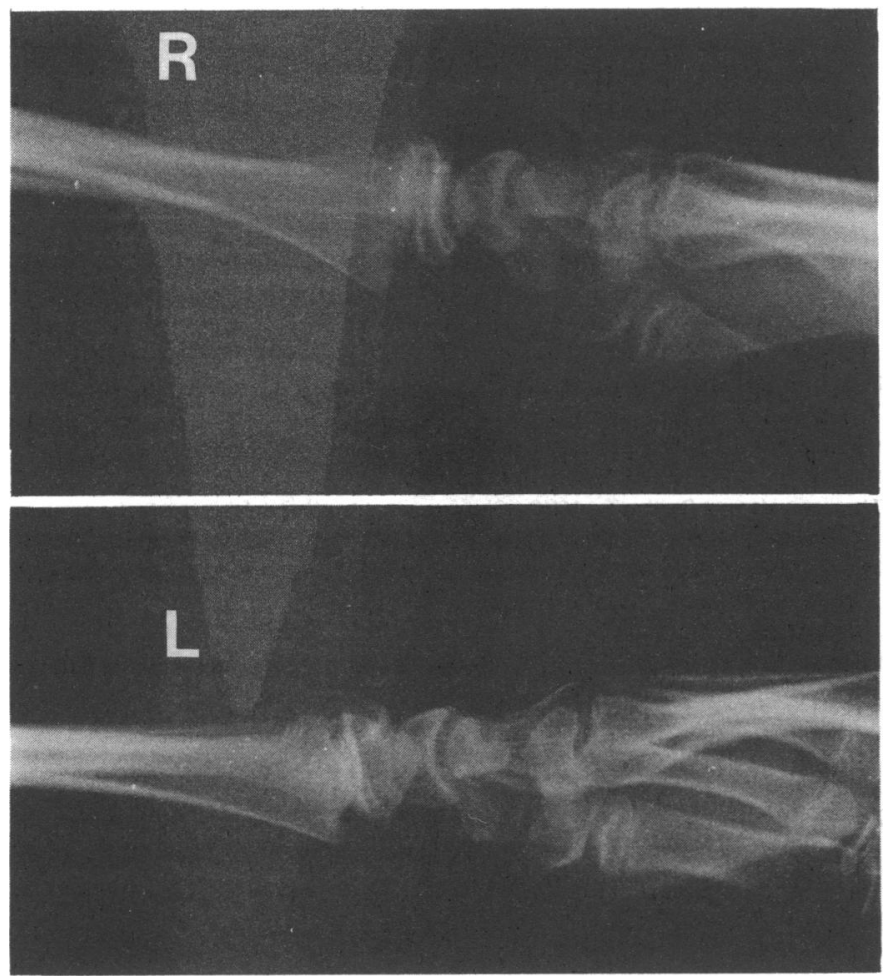

Fig. 1: Lateral radiograph demonstrating bilateral Salter-Harris Type II fracture-separations of the distal radial epiphyses.

\section{Address for correspondence:}

Mr. N. H. Jenkins

Prince of Wales Orthopaedic Hospital

Rhydlafar

Cardiff

South Glamorgan

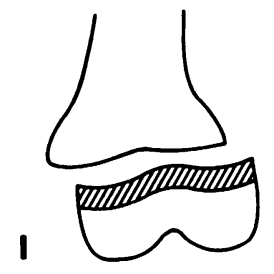

II

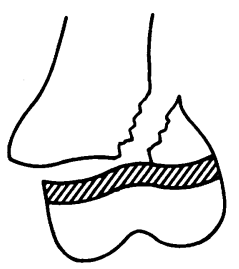

III

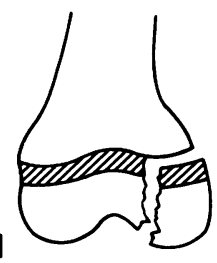

IV

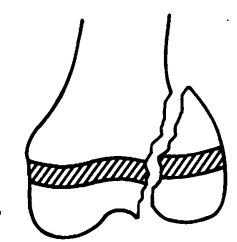

v

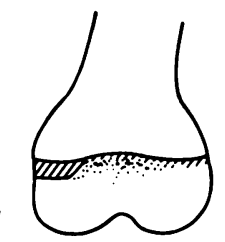

Fig. 2: The Salter-Harris Classification of Epiphyseal Injuries.

showed bilateral Salter-Harris Type II fracture-separations of the distal radial epiphyses (Figs. 1 and 2). The fractures were reduced under anaesthetic and held in plaster.

Two weeks later, whilst still in plaster, the boy injured his left ankle in a football tackle sustaining a triplane fracture of the distal tibial epiphysis (Fig. 3). The displacement as seen in the A-P view (Tillaux component) was reduced and held with a transversely placed cancellous screw, the ankle was then treated in plaster.

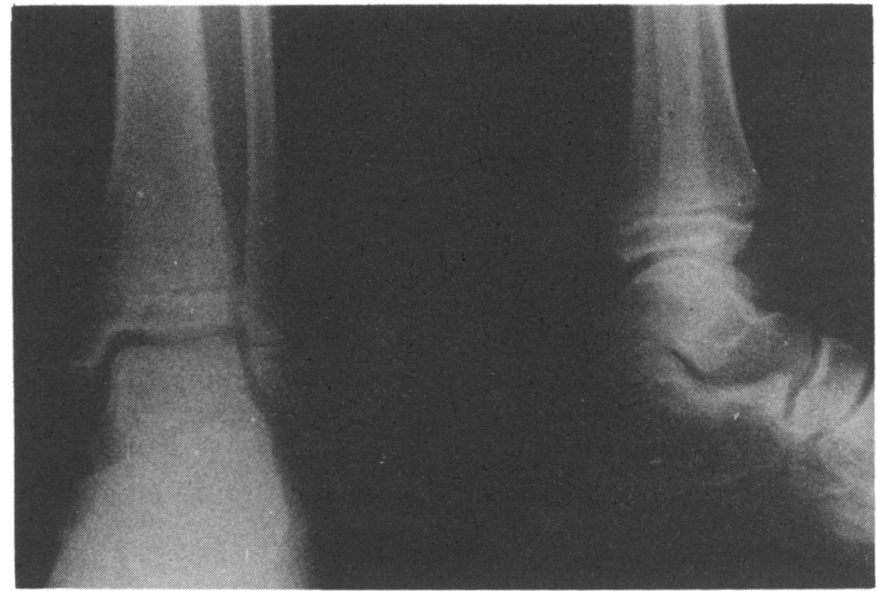

Fig. 3: Radiographs of the left ankle illustrating the Tillaux (A-P view) and Salter-Harris Type II (lateral view) components of the tri-plane fracture.

\section{DISCUSSION}

This case is reported for two reasons. Firstly the combination of three separate epiphyseal injuries occurring within a fortnight is very unusual, and one of this boy's injuries, that to the ankle, is of a type sufficiently rare as not to be taken into account in the almost universally used 
Salter-Harris classification (Cooperman et al, 1980; Rang, 1983). The second and most important reason for reporting this case is to draw attention to the dangers of weight-lifting by school children. Both weight-lifting and, more especially weight-training, are becoming increasingly popular at schools. However both schools and sports clubs forbid unsupervised weight-lifting and insist on the accompanying presence of "spotters" at all times. Should parents purchase such sports equipment in order that their children may further pursue these activities at home it is the parents' responsibility both to educate them and to supervise them in its use at all times.

\section{ACKNOWLEDGEMENT}

We would like to thank Mr. Jack Lewis (Head of Physical Education Department, Cardiff High School) for his advice during the preparation of this report.

\section{References}

Cooperman, D. R., Spiegal, P. G. and Laros, G. S., 1980 "Tibial fractures involving the ankle joint in children: The so-called triplane epiphyseal fracture". J.Bone Joint Surg.(Am.) 60A: 1040-1050.

Rang, M. (Ed.), 1983 "Injuries of the epiphysis, growth plate, and the perichondral ring". Children's Fractures. 2nd Edition. J. B. Lippincott Co., Philadelphia.

\section{BOOK REVIEW}

Title:

\section{DEATH IN THE LOCKER ROOM}

Author: Bob Goldman

Publisher: Icarus Press, South Bend, Indiana. 1984

Price: $\$ 19.95$

Cloth bound

ISBN 0-89651-155-3

Death in the Locker Room was written following seven years research by an American biologist who saw to of his friends die as a result of taking anabolic steroids. His research took the form of reading all the available text books, research articles and journals, together with interviews with athletes, coaches, physicians and researchers. He describes how anabolics are taken, who takes them, why and what kind of side effects occur. He also deals with the philosophical aspect as to how athletes feel about taking drugs.

He defines two groups of drugs, the restorative (therapeutic) and the ergogenic. He defines three types of sports physicians, those who give both groups of drugs, those who prescribe restorative drugs only and those who prescribe nothing while an athlete competes. He points out the grey areas between the therapeutic (restorative drugs), and the ergogenic group but does not answer the question as to where the line shall be drawn. He does however give useful recommendations to any physician involved with treating athletes.

The book is a personal statement that drugs, especially anabolics, have no place in sport and is best kept in a library as a reference. It is liberally illustrated and includes about 1,000 references.

P. L. Thomas 